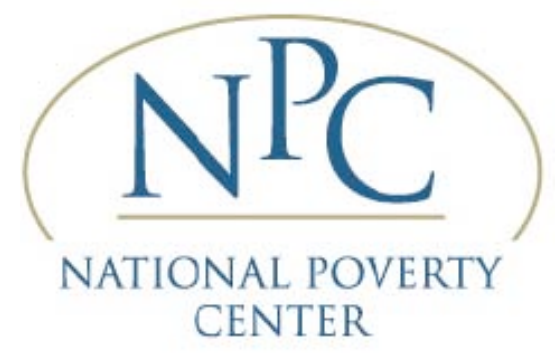

National Poverty Center Working Paper Series

$\# 05-2$

March 2005

\title{
The GINI Coefficient and Segregation on a Continuous Variable
}

\author{
Jeongdai Kim, University of Texas at Dallas
}

Paul A. Jargowsky, University of Texas at Dallas

This paper is available online at the National Poverty Center Working Paper Series index at: http://www.npc.umich.edu/publications/working_papers/ 


\title{
The GINI Coefficient and Segregation on a Continuous Variable*
}

\author{
Jeongdai Kim \\ University of Texas at Dallas \\ (jdkim@utdallas.edu) \\ Paul A. Jargowsky \\ University of Texas at Dallas \\ (jargo@utdallas.edu)
}

\begin{abstract}
The Gini Index is a widely used measure of income inequality. It has also been used as a segregation measure, but only in the case of binary variables, e.g. race or gender. We develop a general version of the Gini Index that can accommodate either continuous or binary variables, and discuss its relationship to existing measures. Using the Public Use Microdata Sample from the 2000 Census, we illustrate the calculation of the Index and show that it is highly correlated with an existing measure of economic segregation.
\end{abstract}

Approximate Word Count: 1,800

Classification Code: C43, D31, D63

Key words: Gini, Segregation, Inequality, Economic Segregation

\footnotetext{
* The authors wish to thank Brian Berry, Marie Chevrier, and Rebecca Yang for helpful comments and suggestions. We also thank the Centre de Sciences Humaines in New Delhi, India, where Paul Jargowsky was a Visiting Scholar when this paper was written.
} 


\section{The GINI Coefficient and Segregation on a Continuous Variable}

\section{BACKGROUND}

Segregation is not only a social issue but also an economic issue that is closely related to the economic inequality and development. However, the issue has not received much attention in the literature. One of the reasons, we believe, is that there are few measures of segregation for economic variables such as income, since segregation measures are mainly developed for dichotomous variables such as the gender gap in occupations (Deutsch et al. 1994; Fluckiger and Silber 1990) and Black/White segregation (Carrington and Troske 1998; Duncan and Duncan 1955). A typical approach for a continuous variable has been to divide the continuous variable into two or more discrete categories, and then employ the traditional group-based measures (Massey and Eggers 1991). This approach has been criticized for discarding information and for potentially confounding changes in the underlying parameters of the continuous variable's distribution with changes in segregation (Jargowsky 1996). The Neighborhood Sorting Index (NSI), a version of eta squared, has been used to measure income segregation (Jargowsky 1996). However, without comparable measures, the performance of NSI has not been examined. This note aims to provide a valid measure of segregation for continuous variables based on the Gini coefficient.

From a measurement perspective, segregation is by definition a way of grouping units, whereas inequality is not. Segregation concerns the allocation of primary units with different levels of a characteristic, e.g. persons of different races or households of different incomes, among the subgroups of a larger group, e.g. neighborhoods within a 
metropolitan area. Inequality, in contrast, examines the distribution of a characteristic of the primary units within a given group, with no regard for the membership of those units to subgroups.

The GINI coefficient (G) is a common measure of income inequality (Gini 1912, 1921). It has also been employed as a measure of segregation, although in that context, its use has generally been limited to dichotomous groups (Silber 1989; James and Taueber 1985; Massey and Denton 1988). ${ }^{1}$ We show how a modified version of the Gini Coefficient can be used as a segregation measure for continuous variables, a task for which there are few alternative measures (White 1986). To measure segregation along a continuous dimension, we modify $G$ based on the idea of Jahn, Schmid and Schrag (1947) and compare it to NSI. In this note, we use household income as an example, but the argument is applicable to any continuous variable.

\section{THE GEOMETRY OF THE INDEX}

As shown in Figure 1, the Lorenz curve relates the cumulative percentage of total household income, sorted from lowest to highest income, as a function of the cumulative percent of total households (Lorenz 1905). The Gini Coefficient of Income Inequality is defined as the area between the Lorenz curve and the line of equality, divided by the total area under the line of the equality. In Figure 1, assume that $L_{i}$ is a Lorenz curve based

\footnotetext{
${ }^{1}$ These measures have been extended to handle multiple racial and ethnic categories (James 1986; Morgan 1975; Reardon and Firebaugh 2002; Sakoda 1981; Silber 1989).
} 
on data sorted by individual household income, and $L_{n}$, sorted by neighborhood means of household incomes. ${ }^{2}$ The inequality index of individual households $\left(G^{i}\right)$ is defined by:

$$
G^{i}=\left(A_{1}+A_{2}\right) /\left(A_{1}+A_{2}+B\right) .
$$

The Gini Coefficient of Neighborhood Inequality $\left(\mathrm{G}^{\mathrm{n}}\right)$ with $L_{n}$ is calculated in an analogous manner to $\mathrm{G}^{\mathrm{i}}$ :

$$
G^{n}=A_{1} /\left(A_{1}+A_{2}+B\right)
$$

$G^{n}$ is conceptually inappropriate as a measure of segregation, because it simply measures the inequality of groups without conveying any information on how the distribution changes when individual units are aggregated into groups while segregation is the degree of group separation given the distribution of individual units. ${ }^{3}$ Nor does $G^{n}$ provide any sense of the degree of segregation because its upper bound varies depending on the distribution of individual units. When all neighborhoods have the same mean income, $G^{\text {n }}$ takes a value of zero. However, when there is maximal segregation - every household living in neighborhoods with other households of an income - the Lorenz curve for neighborhoods $\left(L_{n}\right)$ converges to the Lorenz curve for individuals $\left(L_{i}\right)$ and the upper bound of $G^{n}$ is determined by $G^{i}$.

Jahn, Schmid and Schrag (1947) introduced the ratio of $G^{n}$ to the value of $G$ which would obtain if where were complete segregation as a measure of Black-White segregation. Although it was proposed for a dichotomous case, extending their idea by

\footnotetext{
${ }^{2}$ It is obvious that $L_{n}$ is always above or on $L_{i}$.

${ }^{3}$ Hutchens (2004) is an example of a work that assumes $G^{n}$ is a measure of segregation.
} 
scaling $G^{n}$ with $G^{i}$ solves the conceptual and measurement problems. The Gini Coefficient of Segregation $\left(G^{S}\right)$ is defined as:

$$
G^{s}=\frac{G^{n}}{G^{i}}=\frac{A_{1} /\left(A_{1}+A_{2}+B\right)}{\left(A_{1}+A_{2}\right) /\left(A_{1}+A_{2}+B\right)}=\frac{A_{1}}{A_{1}+A_{2}} .
$$

Maximum segregation, given the existing income distribution, is indicated by $G^{s}$ being equal to one, and minimum segregation, by zero. $G^{s}$ is a general form of the GINI segregation index that includes binary and continuous variable cases as shown in the next section.

\section{FORMULATION}

Literature on the decomposition of Gini provides various computation methods for $G^{i}$ and $G^{n}$ (Mussard 2004; Pyatt 1976; Silber 1989; Yao 1999). Following the geometrical definition in Figure 1, and the area calculation method shown in Figure 2,

$$
\begin{aligned}
G^{i} & =\left(A_{1}+A_{2}\right) /\left(A_{1}+A_{2}+B\right) \\
& =(0.5-B) / 0.5 \\
& =1-2 B \\
2 B & =\sum_{i=1}^{N}\left(Y_{i-1}+Y_{i}\right)\left(H_{i}-H_{i-1}\right)
\end{aligned}
$$

where $Y_{i}$ and $H_{i}$ are, respectively, cumulative percentages of income and number of households at the $i^{\text {th }}$ household ranked in ascending order by household income from one to N. $G^{n}$ is calculated in an analogous manner, ranking the households in ascending order by mean neighborhood income. Then, given $H_{\mathrm{i}}-H_{\mathrm{i}-1}=1 / \mathrm{N}$, 


$$
G^{s}=\frac{G^{n}}{G^{i}}=\frac{1-\sum_{i=1}^{N}\left(Y_{n i-1}+Y_{n i}\right)\left(H_{i}-H_{i-1}\right)}{1-\sum_{i=1}^{N}\left(Y_{i-1}+Y_{i}\right)\left(H_{i}-H_{i-1}\right)}=\frac{N-\sum_{i=1}^{N}\left(Y_{n i-1}+Y_{n i}\right)}{N-\sum_{i=1}^{N}\left(Y_{i-1}+Y_{i}\right)}
$$

In (6), $Y_{n i}$ is the cumulative percentage of average household income of the neighborhood in which the $i^{\text {th }}$ household resides. Formula, (6) is a general form applicable to both binary and continuous variable cases. Extending Anand (1983), (6) can be also expressed in the form of mean difference Gini as follows.

$$
G^{s}=\frac{G^{n}}{G^{i}}=\frac{\frac{1}{2 N^{2} m} \sum_{i=1}^{N} \sum_{j=1}^{N}\left|y_{n i}-y_{n j}\right|}{\frac{1}{2 N^{2} m} \sum_{i=1}^{N} \sum_{j=1}^{N}\left|y_{i}-y_{j}\right|}
$$

where $y_{i}$ is the income of the $i^{\text {th }}$ households, $y_{n i}$ is the average household income of the neighborhood in which the $y_{i}$ household resides, and $m$ is the overall mean income.

To see the applicability of (6) and (7) to binary cases, assume that there are $B$ Blacks and $W$ Whites in $T$ population $(T=B+W)$, assign a value of one for each Black and zero for each White, define $P=(B / T)$, and consider Lorenz curves in two dimensional space of the percentage population (horizontal axis) and the percentage Black (vertical axis). Then, in (7), $m$ is replaced with $P, y_{i}$ equals one for Black and zero for White, $Y_{i}$ will be the cumulative percentage of Black to the total population, $y_{n i}$ is the proportion Black in the $i^{\text {th }}$ household's neighborhood, and its cumulative percentage is $Y_{n i}$. Since $G^{i}$, the denominator of $G^{s}$ in (7), becomes $1-P$,

$$
G^{s}=\frac{\sum_{i=1}^{N} \sum_{j=1}^{N}\left|P_{n i}-P_{n j}\right|}{2 N^{2} P(1-P)}
$$


where the proportion of Black in the $i^{\text {th }}$ household's neighborhood, $y_{n i}$, is replaced with $P_{n i}$ for the consistency of terminology. (8) is the formula frequently used in the literature for binary segregation cases. Thus, it is clear that (6) and (7) are general forms of the Gini segregation index that include binary cases.

We will contrast $\mathrm{G}^{\mathrm{s}}$ with the Neighborhood Sorting Index (NSI), which is based on the idea that there is a distribution of individual household incomes and a distribution of neighborhood mean incomes. To the extent that individuals of different incomes reside in neighborhoods together, the dispersion of neighborhood income will be less than the dispersion of household income (Jargowsky 1996). Thus, the NSI may be expressed as:

$$
N S I=\sqrt{\frac{\text { Variance Between Neighborhoods }}{\text { Total Variance }}}=\sqrt{\frac{\sum_{i=1}^{N}\left(y_{n i}-m\right)^{2}}{\sum_{i=1}^{N}\left(y_{i}-m\right)^{2}}}
$$

where $y_{n i}$ is the average income of the neighborhood to which the $i^{\text {th }}$ household belongs. NSI attains a minimum of 0 when all neighborhood mean incomes are equal to area-wide mean income, so there is no variance between neighborhoods. It attains a theoretical maximum of 1 when all persons live only with others who have identical incomes, so that all variance in household income is between neighborhoods. The square of this measure is equivalent to eta squared from a one-way analysis of variance in which the categorical variable is neighborhood. 


\section{EMPIRICAL APPLICATION}

For the purpose of illustration, we use the 5-percent Public Use Microdata Sample (PUMS) from the 2000 U.S. Census (Ruggles 2004). The data is a 5 percent sample of all U.S. households, a subset of the households that completed the 2000 Census "long form" survey. Two levels of geography are employed: 1) the 25 largest U.S. metropolitan areas, and 2) Public Use Microdata Areas (PUMAs), which function as neighborhoods in this analysis. ${ }^{4}$ We exclude households in non-metropolitan areas. Table 1 shows the number of PUMAs, number of sample households, weighted number of total households, and mean household income for the 25 largest metropolitan areas.

Table 2 shows the individual, neighborhood, and income segregation Gini coefficients, as well as the standard deviations of the household and neighborhood income distributions and the Neighborhood Sorting Index. Metropolitan areas vary little from each other in terms of income inequality, but have very different levels of sorting across neighborhoods. $\mathrm{G}^{\mathrm{s}}$ and NSI rank metropolitan areas in a very similar fashion.

Figure 3 shows the near perfect correspondence between the NSI and the $\mathrm{G}^{\mathrm{s}}$ in the sample of 25 metropolitan areas. The Pearsonian correlation coefficient is 0.9771 , and it is highly significant. Clearly, these measures are tapping into a common underlying phenomenon. However, the NSI, as a function of squared deviations, is known to give greater weight to higher incomes than GINI, which does not overweight any segment of

\footnotetext{
${ }^{4}$ PUMAs are bigger than census tracts, which more frequently served as neighborhood proxies (White 1987). The 25 largest metropolitan areas contain 693 PUMAs. A few PUMAs on the fringes of metropolitan areas including territory in neighboring metropolitan areas or non-metropolitan areas, and thus did not have a metropolitan area code. These PUMAs and the households they contain were excluded from the analysis. The average PUMA size was 50,000 households (weighted), based on an average sample size of 2,250 .
} 
the distribution (James and Taueber 1985; White 1986). This may be considered an advantage in certain applications, particularly those involving smaller, more heterogeneous neighborhood units. However, the optimal weighting depends on the researcher's implicit social welfare function (Atkinson 1970; Dalton 1920).

In the absence of individual-level data, both measures present a challenge to researchers. In the case of NSI, the total household variance must be estimated from the aggregated data (Jargowsky 1995: Appendix A). In the case of $\mathrm{G}^{\mathrm{s}}$, a distribution of the individual household incomes must be assumed. In a highly skewed distribution, as is typical for income, the variance may be more difficult to estimate accurately than the mean, because of the higher penalty for misestimating the incomes and deviations in the open-ended top bracket. This is an advantage for the Gini approach.

\section{CONCLUSION}

The Gini Index of Neighborhood Inequality, $G^{n}$, the application of the Gini Index to neighborhood-level income, is not a measure of economic segregation. Rather it is a mixture of information about the inequality of the income distribution and the ameliorative effects of neighborhood heterogeneity. Normalizing the neighborhood-level Gini by the individual-level Gini provides a measure of segregation, and provides an alternative measure of economic segregation that may be easier to estimate in many cases than the Neighborhood Sorting Index. In our application to household income in U.S. metropolitan areas, the two measures were highly correlated across 25 metropolitan areas. In general, the Gini Index of Segregation may be used with either continuous or dichotomous variables. 


\section{References}

Anand, S. (1983) Inequality and Poverty in Malaysia: Measurement and Decomposition. Oxford: Oxford University Press.

Atkinson, A. B. (1970) On the measurement of inequality. American Sociological Review, 43, 86580 .

Carrington, W.J. \& Troske, K. R. (1998) Interfirm segregation and the black/white wage gap. Journal of Labor Economics, 16, 231-260.

Dalton, H. (1920) Measurement of the inequality of income. The Economic Journal, 30, 348-61.

Deutsch, J., Fluckiger, Y., \& Silber, J. (1994) Measuring occupational segregation. Journal of Econometrics, 61, 133-146.

Duncan, O. D. \& Duncan, B. (1955) A methodological analysis of segregation measures. American Sociological Review, 20, 210-217.

Fluckiger, Y. \& Silber, J. (1990) Career choice and the measurement of segregation by sex in employment: the case of students in Switzerland. Pp. 97-108 in Modeling the Labor Market, Proceedings of the Meeting of the Applied Econometrics Association, Stasbourg.

Gini, C. (1912) Variabilita e mutabilita. Reprinted in E. Pizetti \& T. Salvemini, eds., Memorie di Metodologia Statistica. Rome: Libreria Erendi Virgilio Veschi, 1955.

. (1921) Measurement of Inequality of Incomes. The Economic Journal, 31, 124-126.

Hutchens, R. (2004) One Measure of Segregation. International Economic Review, 45, 555-578.

Jahn, J., Schmid, C. F. \& Schrag, C. (1947) The measurement of ecological segregation. American Sociological Review, 3, 293-303.

James, D. R. \& Taeuber, K. E. (1985) Measures of Segregation. Sociological Methodology, 15, 1-32.

James, F. J. (1986) A new generalized 'exposure-based' segregation index. Sociological Methods and Research, 14, 301-316.

Jargowsky, P. A. (1995) Take the money and run: economic segregation in U.S. metropolitan areas. Discussion Paper 1056-95 (January 1995). Madison, Wisconsin: Institute for Research on Poverty.

(1996) Take the money and run: economic segregation in U.S. metropolitan areas. American Sociological Review, 61, 984-998.

Lorenz, M. O. (1905) Methods for measuring the concentration of wealth. American Statistical Association, 9, 209-219. 
Massey, D. S. \& Denton, N. A. (1988) The dimensions of racial segregation. Social Forces, 67, 281305.

Massey, D. S. \& Eggers, M. L. (1991) The ecology of inequality: minorities and the concentration of poverty, 1970-1980. American Journal of Sociology, 95, 1153-1188.

Morgan, B. S. (1975) The segregation of socioeconomic groups in urban areas: a comparative analysis. Urban Studies, 12, 47-60.

Mussard, S. (2004) The bidimensional decomposition of the Gini ratio. A case study: Italy. Applied Economics Letters, 11, 503-505.

Pyatt, G. (1976) On the interpretation and disaggregation of Gini coefficients. Economics Journal, 86, 243-255.

Reardon, S. F. \& Firebaugh, G. (2002) Measures of multigroup segregation. Sociological Methodology, 32, 33-67.

Ruggles, S., Sobek, M., Alexander, T., Fitch, C. A., Goeken, R., Hall, P. K., King, M. \& Ronnander, C. (2004) Integrated Public Use Microdata Series: Version 3.0 [Machine-readable database]. Minneapolis, MN: Minnesota Population Center. Accessed at http://www.ipums.org on November 11, 2004.

Sakoda, J. (1981) A generalized index of dissimilarity. Demography, 18, 245-250.

Silber, J. (1989) Factor components, population subgroups and the computation of the Gini index of inequality. The Review of Economics and Statistics, 71, 107-115.

White, M. J. (1986) Segregation and diversity measures in population distribution. Population Index, $52,198-221$. . (1987) American Neighborhoods and Residential Differentiation. New York: Russell Sage Foundation.

Yao, S. (1999) On the decomposition of Gini coefficients by population class and income source: a spreadsheet approach and application. Applied Economics, 31, 1249-1264. 
Figure 1: Lorenz Curves for Individual

Households and Neighborhoods

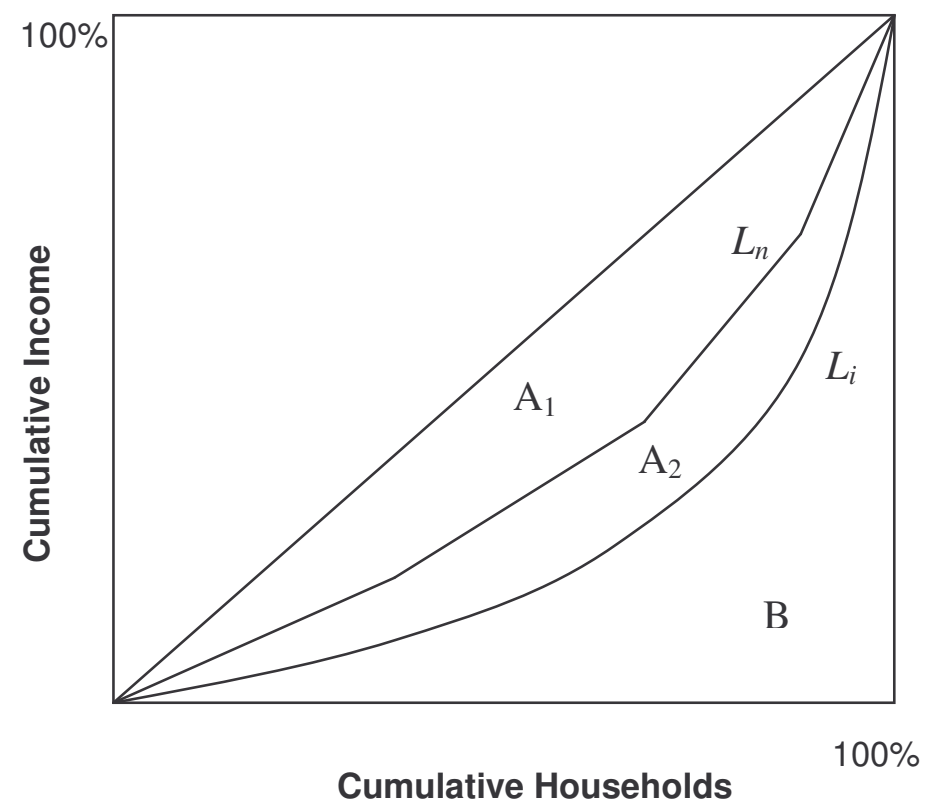


Figure 2: Area Under the Lorenz Curve

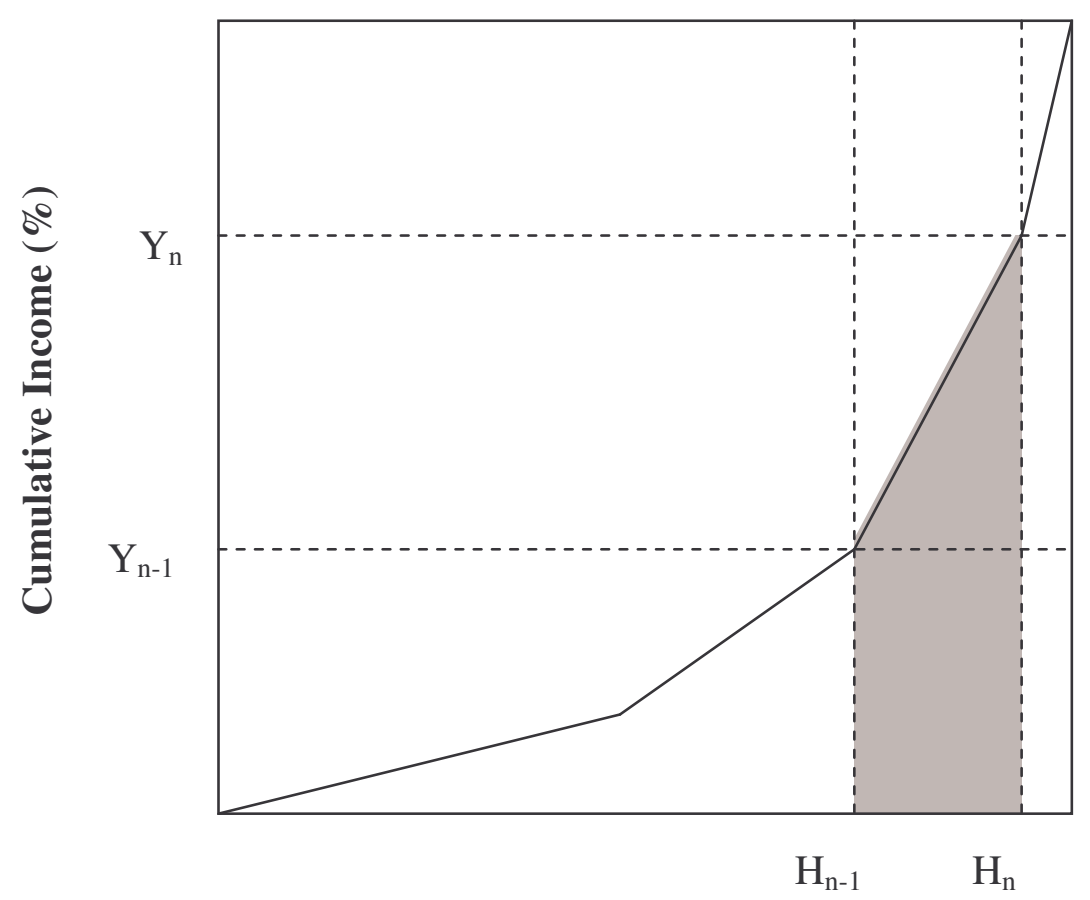

Cumulative Households (\%) 
Figure 3: Economic Segregation in Metropoiltan Areas by PUMS Areas 25 Largest Metropolitan Areas, 2000

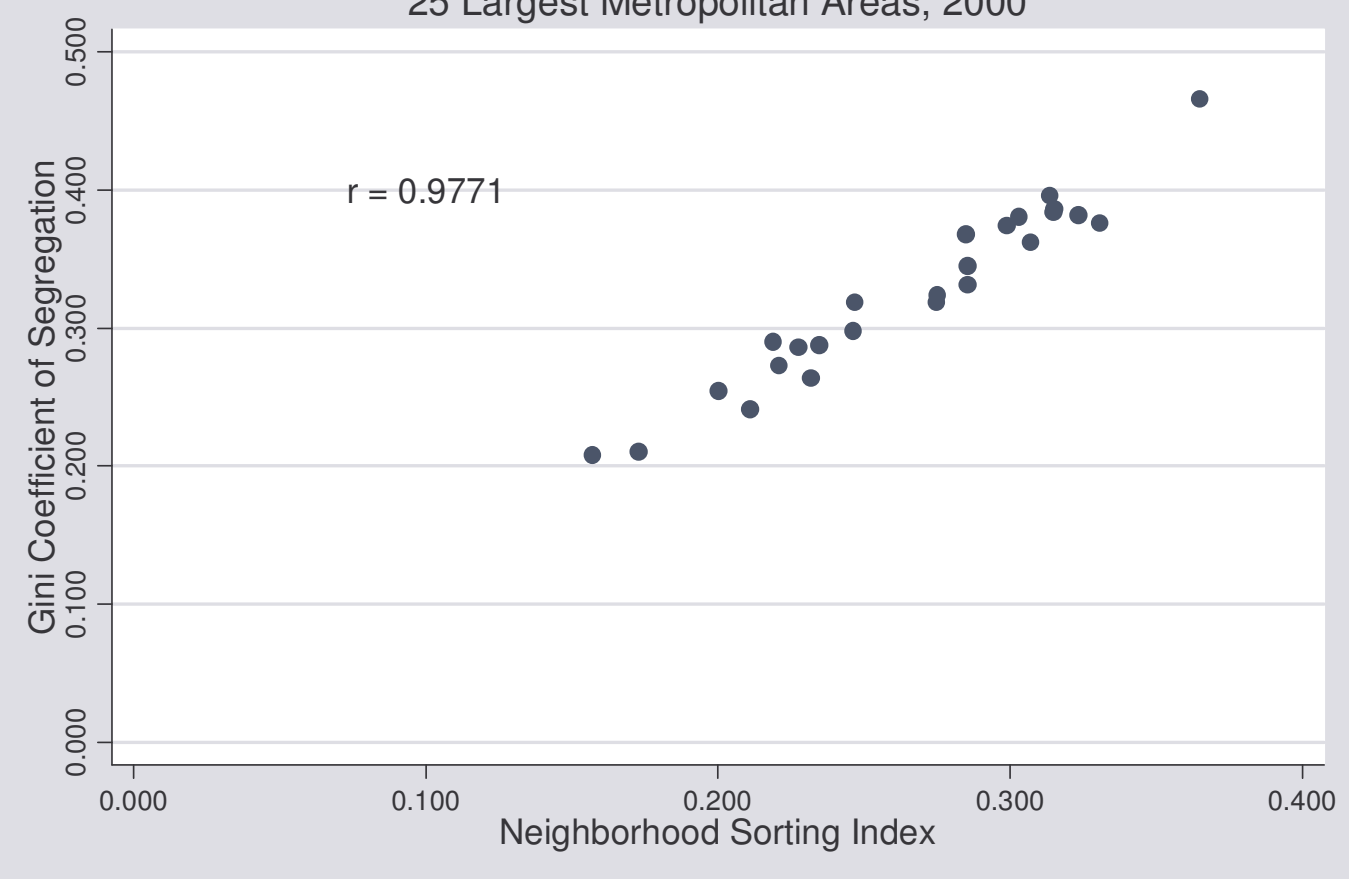




\begin{tabular}{|c|c|c|c|c|c|}
\hline & Metropolitan Area & Households & $\begin{array}{c}\text { Sample } \\
\text { Size }\end{array}$ & $\begin{array}{l}\text { PUMS } \\
\text { Areas } \\
\end{array}$ & $\begin{array}{c}\text { Mean Houshold } \\
\text { Income (\$) }\end{array}$ \\
\hline 1 & New York-Northeastern NJ & $3,482,324$ & 144,070 & 64 & 62,237 \\
\hline 2 & Los Angeles-Long Beach, CA & $3,135,972$ & 154,419 & 67 & 60,975 \\
\hline 3 & Chicago-Gary-Lake, IL & $2,937,970$ & 122,571 & 54 & 68,059 \\
\hline 4 & Philadelphia, PA/NJ & $1,913,900$ & 79,438 & 37 & 62,560 \\
\hline 5 & Washington, DC/MD/VA & $1,777,008$ & 86,350 & 33 & 80,813 \\
\hline 6 & Detroit, MI & $1,692,431$ & 66,836 & 32 & 63,025 \\
\hline 7 & Houston-Brazoria, TX & $1,462,022$ & 63,582 & 30 & 61,519 \\
\hline 8 & Atlanta, GA & $1,460,471$ & 64,092 & 32 & 67,331 \\
\hline 9 & Boston, MA & $1,320,037$ & 62,541 & 29 & 74,018 \\
\hline 10 & Dallas-Fort Worth, TX & $1,225,886$ & 56,568 & 23 & 66,613 \\
\hline 11 & Phoenix, AZ & $1,133,243$ & 53,493 & 22 & 59,445 \\
\hline 12 & Minneapolis-St. Paul, MN & $1,096,388$ & 38,674 & 21 & 67,598 \\
\hline 13 & Riverside-San Bernadino, CA & $1,033,275$ & 48,449 & 20 & 54,767 \\
\hline 14 & St. Louis, MO-IL & $1,011,780$ & 41,947 & 19 & 57,295 \\
\hline 15 & Tampa-St. Petersburg-Clearwater, FL & $1,007,772$ & 49,057 & 20 & 50,889 \\
\hline 16 & San Diego, CA & 993,065 & 47,749 & 16 & 63,224 \\
\hline 17 & Baltimore, MD & 958,948 & 44,495 & 22 & 62,919 \\
\hline 18 & Orange County, CA & 936,488 & 47,397 & 17 & 77,994 \\
\hline 19 & Pittsburgh-Beaver Valley, PA & 934,238 & 42,066 & 17 & 50,563 \\
\hline 20 & Seattle-Everett, WA & 932,566 & 40,990 & 20 & 69,043 \\
\hline 21 & Nassau Co, NY & 916,196 & 47,392 & 24 & 87,956 \\
\hline 22 & Cleveland, $\mathrm{OH}$ & 892,471 & 43,189 & 19 & 55,224 \\
\hline 23 & Oakland, CA & 866,144 & 42,740 & 18 & 77,483 \\
\hline 24 & Denver-Boulder-Longmont, CO & 776,515 & 34,314 & 18 & 64,667 \\
\hline 25 & Miami-Hialeah, FL & 768,759 & 36,750 & 19 & 51,955 \\
\hline & 25 Metropolitan Areas & $34,665,869$ & $1,559,169$ & 693 & 64,842 \\
\hline
\end{tabular}

Source: 2000 Public Use Microdata 5\% Sample, U.S. Bureau of the Census. Tabulation by the authors. Notes: Includes households in PUMAs with identified metropolitan areas. All computations, except sample size and PUMS areas, use the PUMS sample weight. 


\section{Table 2: Gini Coefficients and Standard Deviations of Individual and Neighborhood Income Distributions, and Economic Segregation Measures, 25 Largest U.S. Metropolitan Areas, 2000.}

\begin{tabular}{|c|c|c|c|c|c|c|c|}
\hline & Metropolitan Areas & $\begin{array}{c}\text { Income } \\
\text { Inequality } \\
G^{i}\end{array}$ & $\begin{array}{l}\text { Coefficient } \\
\text { Neighbor- } \\
\text { hood } \\
\text { Inequality } \\
\text { G }^{n}\end{array}$ & $\begin{array}{c}\text { Segre- } \\
\text { gation } \\
\mathrm{G}^{\mathrm{s}}\end{array}$ & $\begin{array}{l}\text { Individual } \\
\text { Household } \\
\text { Income }\end{array}$ & $\begin{array}{l}\text { Neighbor- } \\
\text { hood Mean } \\
\text { Income }\end{array}$ & $\begin{array}{l}\text { Neighbor- } \\
\text { hood } \\
\text { Sorting } \\
\text { Index } \\
\text { (NSI) }\end{array}$ \\
\hline 1 & New York-Northeastern NJ & 0.535 & 0.249 & 0.465 & 79,189 & 28,905 & 0.365 \\
\hline 2 & Los Angeles-Long Beach, CA & 0.496 & 0.185 & 0.374 & 69,626 & 20,806 & 0.299 \\
\hline 3 & Chicago-Gary-Lake, IL & 0.456 & 0.173 & 0.381 & 69,145 & 20,972 & 0.303 \\
\hline 4 & Philadelphia, PA/NJ & 0.462 & 0.183 & 0.395 & 63,655 & 19,971 & 0.314 \\
\hline 5 & Washington, DC/MD/VA & 0.428 & 0.155 & 0.362 & 73,974 & 22,720 & 0.307 \\
\hline 6 & Detroit, MI & 0.444 & 0.167 & 0.376 & 61,382 & 20,299 & 0.331 \\
\hline 7 & Houston-Brazoria, TX & 0.470 & 0.150 & 0.318 & 65,164 & 16,098 & 0.247 \\
\hline 8 & Atlanta, GA & 0.440 & 0.152 & 0.345 & 65,606 & 18,734 & 0.286 \\
\hline 9 & Boston, MA & 0.471 & 0.152 & 0.324 & 76,594 & 21,070 & 0.275 \\
\hline 10 & Dallas-Fort Worth, TX & 0.459 & 0.132 & 0.288 & 69,182 & 16,233 & 0.235 \\
\hline 11 & Phoenix, AZ & 0.439 & 0.140 & 0.318 & 57,938 & 15,926 & 0.275 \\
\hline 12 & Minneapolis-St. Paul, MN & 0.415 & 0.113 & 0.272 & 61,455 & 13,579 & 0.221 \\
\hline 13 & Riverside-San Bernadino, CA & 0.437 & 0.092 & 0.211 & 51,986 & 8,981 & 0.173 \\
\hline 14 & St. Louis, MO-IL & 0.440 & 0.169 & 0.384 & 56,637 & 17,825 & 0.315 \\
\hline 15 & Tampa-St. Petersburg-Clearwater, FL & 0.455 & 0.095 & 0.208 & 53,873 & 8,459 & 0.157 \\
\hline 16 & San Diego, CA & 0.454 & 0.135 & 0.298 & 64,302 & 15,840 & 0.246 \\
\hline 17 & Baltimore, MD & 0.438 & 0.169 & 0.386 & 59,543 & 18,763 & 0.315 \\
\hline 18 & Orange County, CA & 0.446 & 0.127 & 0.286 & 76,229 & 17,356 & 0.228 \\
\hline 19 & Pittsburgh-Beaver Valley, PA & 0.462 & 0.117 & 0.254 & 53,833 & 10,777 & 0.200 \\
\hline 20 & Seattle-Everett, WA & 0.436 & 0.105 & 0.241 & 67,626 & 14,271 & 0.211 \\
\hline 21 & Nassau Co, NY & 0.435 & 0.115 & 0.264 & 83,193 & 19,291 & 0.232 \\
\hline 22 & Cleveland, $\mathrm{OH}$ & 0.451 & 0.166 & 0.368 & 56,746 & 16,175 & 0.285 \\
\hline 23 & Oakland, CA & 0.451 & 0.172 & 0.382 & 74,870 & 24,204 & 0.323 \\
\hline 24 & Denver-Boulder-Longmont, CO & 0.432 & 0.143 & 0.331 & 62,140 & 17,738 & 0.285 \\
\hline 25 & Miami-Hialeah, FL & 0.509 & 0.148 & 0.290 & 63,666 & 13,943 & 0.219 \\
\hline & 25 Metropolitan Areas & 0.462 & 0.160 & 0.345 & 67,051 & 19,003 & 0.281 \\
\hline
\end{tabular}

